\title{
Cardioprotective Effect of a Hemoglobin-Based Oxygen Carrier on Cold Ischemia/Reperfusion Injury
}

\author{
Li Wei $^{a}$ Ruo-Bin Wu ${ }^{a}$ Cheng-Min Yang ${ }^{c}$ Shao-Yi Zheng ${ }^{a}$ Xi-Yong Yu ${ }^{b}$ \\ ${ }^{a}$ Department of Cardiovascular Surgery and ${ }^{b}$ Research Center, Guangdong Cardiovascular Institute, \\ Guangdong General Hospital, Guangdong Academy of Medical Sciences, Guangzhou, and 'Institute of \\ Tianjin Union Biotechnology Development, Tianjin, China
}

\section{Key Words}

Hemoglobin-based oxygen carrier • Ischemia/reperfusion injury $\cdot$ Inflammation $\cdot$ Toll-like receptors

\begin{abstract}
Objectives: The etiology of myocardial ischemia/reperfusion (I/R) injury is multifactorial, but activation of the innate immune system and the resulting inflammatory response are important components of I/R injury. The aim of this study was to investigate the protective effect of a hemoglobin-based oxygen carrier (HBOC) on cold I/R heart and to explore the underlying mechanisms. Methods: Isolated Sprague-Dawley rat hearts were perfused in the Langendorff mode. After 30 min of basal perfusion, rat hearts were arrested with histidine-tryptophan-ketoglutarate solution (HTKs) with or without an HBOC and hypothermically stored $\left(4^{\circ} \mathrm{C}\right.$ ) for 9 or $14 \mathrm{~h}$, followed by $2 \mathrm{~h}$ of reperfusion. Results: Compared with HTKs alone, the HBOC in HTKs greatly improved heart contraction and decreased infarct size, necrosis and apoptosis, which was related to the reduced expression of Toll-like receptor 2 (TLR 2), TLR 4, TNF- $\alpha$, IL-1 $\beta$ and nuclear factor $-\kappa B(N F-\kappa B)$ activation. Conclusions: Our results demonstrated that the $\mathrm{HBOC}$ protected isolated rat
\end{abstract}

heart from cold I/R injury and this protection was associated with attenuation of the expression of the TLR 2 and TLR 4/ NF- $\kappa B$ signaling pathway, which may down-regulate the inflammatory response.

Copyright $\odot 2011$ S. Karger AG, Basel

\section{Introduction}

Ischemia/reperfusion (I/R) injury may lead to myocardial contractile dysfunction, cardiac arrhythmias, myocardial infarction and cardiomyocyte apoptosis [1, 2]. Extensive studies have been performed to identify therapeutic strategies that might protect the heart from I/R injury, but most of these have not been applied to patients in the clinical setting due to the lack of a significant effect $[3,4]$. The pathogenesis of I/R injury is complex and reperfusion-induced inflammatory responses play a critical role in mediating myocardial I/R injury. This injury releases cytokines and other inflammatory mediators, initiating a vicious circle of inflammation that exacerbates myocardial damage. Thus, inhibition of the inflammatory response seems a rational way to ameliorate cardiac I/R injury $[5,6]$.

\section{KARGER}

Fax +41613061234 E-Mail karger@karger.ch www.karger.com
Ruo-Bin Wu

Department of Cardiovascular Surgery, Guangdong Cardiovascular Institute Guangdong General Hospital, Guangdong Academy of Medical Sciences 96 Dongchuan Road, Guangzhou 510080 (China)

Tel. +86 208382 7812, ext.10417, E-Mail ruobinwu@163.com 


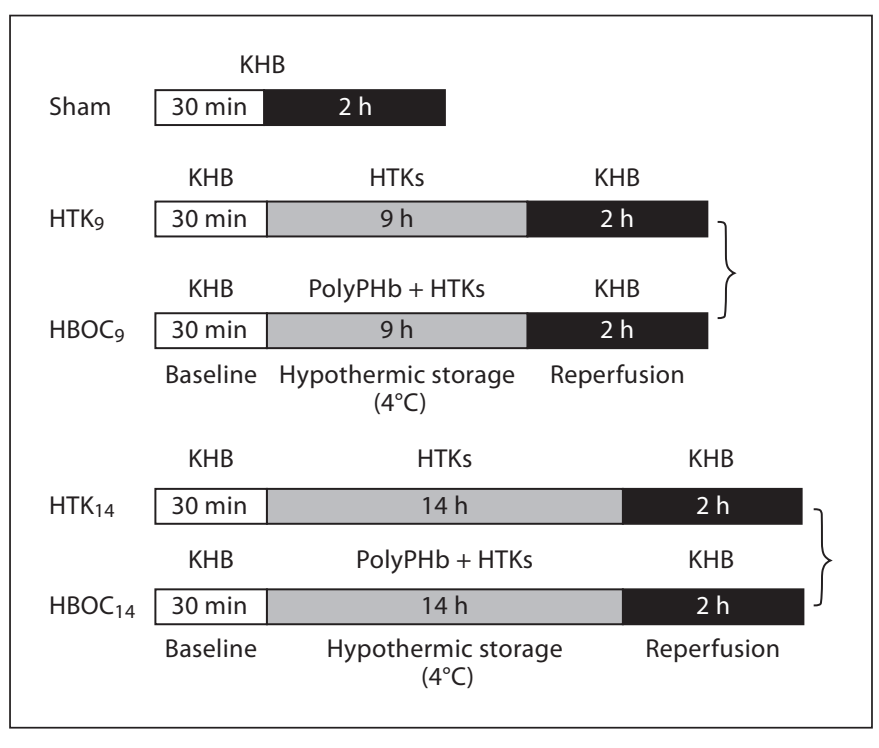

Fig. 1. Schematic representation of the experiment. Immediately after removal from the chest cavity, rat hearts were perfused with $\mathrm{KHB}$ for $30 \mathrm{~min}$ at $37^{\circ} \mathrm{C}$ as baseline and then arrested with HTKs, with or without PolyPHb, and placed in hypothermic storage $\left(4^{\circ} \mathrm{C}\right)$ for $9 \mathrm{~h}\left(\mathrm{HTK}_{9}\right.$ and $\left.\mathrm{HBOC}_{9}\right)$ or $14 \mathrm{~h}\left(\mathrm{HTK}_{14}\right.$ and $\left.\mathrm{HBOC}_{14}\right)$. Hearts were then reperfused with $\mathrm{KHB}$ for $2 \mathrm{~h}$. The sham control group was subjected to $150 \mathrm{~min}$ of perfusion without I/R injury.

Toll-like receptors (TLRs) are a family of molecules that play a critical role in innate immunity. TLRs are evolutionarily conserved transmembrane receptors that serve as pattern recognition receptors, recognizing conserved microbial motifs in molecules. Activation of TLRs by any of these molecules results in an inflammatory response, alerting the host to the presence of a microbial invasion and initiating an immune response. Recent observations demonstrate that some TLR family members, such as TLR 2 and TLR 4, also become activated by endogenous molecules released from damaged or ischemic tissues. TLR signals finally activate the transcription factor nuclear factor- $\kappa \mathrm{B}(\mathrm{NF}-\kappa \mathrm{B})$ and permit the activation of proinflammatory cytokine genes, increasing the expression of cytokines and inflammatory mediators to exacerbate organ damage. The TLR/NF- $\kappa$ B signaling pathway plays an important role in initiating the inflammatory response in I/R [7-9].

Hemoglobin-based oxygen carriers (HBOCs) were initially developed as a blood substitute. Glutaraldehydepolymerized human placenta hemoglobin ( $\mathrm{PolyPHb}$ ) is a particularly promising HBOC because it allows the transport of more oxygen $\left(\mathrm{O}_{2}\right)$ to hypoxic tissues because of its higher affinity for $\mathrm{O}_{2}$, lower viscosity and smaller mean diameter than human red blood cells [10, 11]. Previous studies of HBOCs, including research from our group, demonstrated the potential protective effect of HBOC on the heart against I/R injury, and that the underlying molecular mechanisms quench myocardial oxidative stress and restore the nitroso-redox balance $[12,13]$. However, the protective effect of HBOC on the inflammatory response has not been reported. Thus, this study was designed to investigate the effect of PolyPHb on the TLR/ $\mathrm{NF}-\kappa \mathrm{B}$ signaling pathway in isolated rat heart during cold I/R injury.

\section{Materials and Methods}

All experiments were approved by the Institutional Animal Care and Use Committee of Sun Yat-Sen University and conformed to the Guide for the Care and Use of Laboratory Animals published by the US National Institute of Health (NIH Publication No. 85-23, revised 1996).

\section{PolyPHb Preparation}

PolyPHb was prepared as described previously $[12,13]$. Briefly, hemoglobin from fresh human placenta blood (donated by Tianjin Union Stem Cell and Genetic Engineering Ltd., Tianjin, China) was purified and virally inactivated by heat treatment. Intraand inter-molecular cross-linking were performed using pyridoxal phosphate and glutaraldehyde, respectively. Ultrafiltration and molecular sieve chromatography were performed to harvest the PolyPHb in the molecular weight range of $64-600 \mathrm{kDa}$. The $\mathrm{P}_{50}$ value of PolyPHb was significantly lower than that of fresh human blood (5-9 vs. $26 \mathrm{~mm} \mathrm{Hg}$ ). Prior to use, the PolyPHb was mixed with histidine-tryptophan-ketoglutarate solution (HTKs) to a final concentration of $0.3 \mathrm{~g} \mathrm{Hb} / \mathrm{dl}$, as a cardioplegic solution, and then equilibrated with $100 \% \mathrm{O}_{2}$ gas at $4^{\circ} \mathrm{C}$ for $5 \mathrm{~min}$.

\section{Experimental Protocol}

In total, 75 adult Sprague-Dawley rats, weighing 280-350 g, were injected intravenously with heparin (50 IU) and anesthetized with intraperitoneal sodium pentobarbital $(50 \mathrm{mg} / \mathrm{kg})$. The hearts were rapidly excised, mounted on a Langendorff apparatus (Radnoti, Monrovia, Calif., USA) and perfused with KrebsHenseleit buffer (KHB) at constant pressure $\left(100 \mathrm{~cm} \mathrm{H}_{2} \mathrm{O}\right)$. The $\mathrm{KHB}$ was equilibrated with 95 and $5 \% \mathrm{CO}_{2}$ at $37^{\circ} \mathrm{C}$ for $30 \mathrm{~min}$ prior to use. After $30 \mathrm{~min}$ of basal perfusion, the hearts were randomly divided into 5 groups, arrested with HTKs with or without PolyPHb and stored in $0.9 \%$ sodium chloride under hypothermic storage $\left(4^{\circ} \mathrm{C}\right)$ for $9 \mathrm{~h}$ [HTKs group $\left(\mathrm{HTK}_{9}\right)$ and HBOC group $\left(\mathrm{HBOC}_{9}\right)$ ] or for $14 \mathrm{~h}$ [HTKs group $\left(\mathrm{HTK}_{14}\right)$ and HBOC group $\left.\left(\mathrm{HBOC}_{14}\right)\right]$. The hearts were then reperfused with KHB for $2 \mathrm{~h}$. Rat hearts without arrest were used as the sham control and subjected to $150 \mathrm{~min}$ of perfusion with KHB. The experimental scheme is illustrated in figure 1.

\section{Cardiac Function Measurement}

A water-filled latex balloon was immediately inserted into the left ventricle (LV) via the mitral valve after the heart was mount- 
ed on the Langendorff apparatus. The balloon was attached to a pressure sensor (model SP844; MEMSCAP, Durham, N.C., USA) connected to a PowerLab data-acquisition system (AD Instruments Pty., Bella Vista, N.S.W., Australia). Measured parameters included left ventricular developed pressure (LVDP), left ventricular end-diastolic pressure (LVEDP), maximum LVDP increase $(+\mathrm{dp} / \mathrm{dt})$, and decrease rate $(-\mathrm{dp} / \mathrm{dt})$. Coronary flow $(\mathrm{CF})$ rate was calculated from the coronary effluent, sampling time and cardiac wet weight.

\section{Oxygen Releasing Capacity Determination}

The $\mathrm{O}_{2}$ releasing capacity of PolyPHb was calculated from the $\mathrm{O}_{2}$ partial pressure $\left(\mathrm{pO}_{2}\right)$ and $\mathrm{O}_{2}$ saturation $\left(\mathrm{sO}_{2}\right)$ (i-STAT portable blood gas analyzer; i-STAT Corp, Windsor, N.J., USA) of the cardioplegic solutions $(0.3 \mathrm{~g} \mathrm{Hb} / \mathrm{dl}$ PolyPHb in HTKs or HTKs alone) and the corresponding effluents collected during arrest, using the following formula [12]:

$\mathrm{O}_{2}$ releasing capacity $=\left[\left(\mathrm{pO}_{2} \times \mathrm{sO}_{2}\right)_{\text {cardioplegic solution }}-\left(\mathrm{pO}_{2}\right.\right.$ $\left.\left.\times \mathrm{sO}_{2}\right)_{\text {effluent }}\right] /$ cardiac wet weight.

To assess the levels of anaerobic glycolysis and $\mathrm{O}_{2}$ supply during ischemia, cardiac lactic acid release was also measured from the effluents collected during the first $5 \mathrm{~min}$ of reperfusion (iSTAT portable blood gas analyzer).

Quantitative Real-Time PCR Analysis of mRNA Expression

Rat myocardium samples were homogenized in the TRIZOL reagent (Invitrogen, Carlsbad, Calif., USA). Total RNA concentration and purity were determined by spectrophotometric absorbance measurement (260 and $280 \mathrm{~nm})$. Isolated RNA $(2 \mu \mathrm{g})$ was converted into cDNA using a high-capacity cDNA synthesis kit (TaKaRa, Japan). Real-time PCR (RT-PCR) was performed with an ABI Prism 7,500 sequence detection system (PE Applied Biosystems). The SYBR green RT-PCR master mix kit (TaKaRa, Japan) was used in subsequent PCR assays according to the manufacturer's protocol. The RT conditions were $42^{\circ} \mathrm{C}$ for $15 \mathrm{~min}$ followed by $95^{\circ} \mathrm{C}$ for $2 \mathrm{~min}$; PCR conditions included predenaturing at $95^{\circ} \mathrm{C}$ for $10 \mathrm{~s}$, followed by 40 cycles of $95^{\circ} \mathrm{C}$ for $5 \mathrm{~s}$, of $60^{\circ} \mathrm{C}$ for $30 \mathrm{~s}$ and $72^{\circ} \mathrm{C}$ for $1 \mathrm{~min}$. In this experiment, $18 \mathrm{~S}$ rRNA and GAPDH were used as housekeeping genes. Levels of TLR 2, TLR 4 , TNF- $\alpha$ and IL-1 $\beta$ mRNA were calculated based on the $2^{-\Delta \Delta C t}$ method of comparative quantification $[14,15]$. Primers were as follows:

TLR 2; sense primer 5'-ACGCAGTGAGTGGTGCAAGTAT3'; antisense primer 5'-CTTCTTCAATGGGTTCCAGCAA-3'.

TLR 4; sense primer 5'-TGGTGTAGCCATTGCTGCCAACA3'; antisense primer 5'-AGCGGCTACTCAGAAACTGCCA-3'.

TNF- $\alpha$; sense primer 5'-GAAACACACGAGACGCTGAA-3'; antisense primer 5'-CCACTCAGGCATCGACATTC-3'.

IL-1 $\beta$; sense primer $5^{\prime}$-TCACAGCAGCATCTCGACA-3'; antisense primer 5'-GGAGAGCTTTCAGCTCACAT-3'.

18srRNA; sense primer 5'-CCTGGATACCGCAGCTAGGA3'; antisense primer 5'-GCGGCGCAATACGAATGCCCC-3'

GAPDH; sense primer 5'-GACAACTTTGGCTCGTGGA-3'; antisense primer 5' - ATGCAGGGGTTCTGG-3'.

Western Blot Analysis of Protein Levels

Western blotting was performed with monoclonal antibodies against TLR 2 and TLR 4 (anti-TLR 2, Epitomics, USA; anti-TLR 4, Cell Signaling Technology, USA; diluted 1:1,000). LV tissue was homogenized and the protein concentration of its supernatant was determined by the bicinchoninic acid method (Pierce, Rockford, Ill., USA). Protein $(50 \mu \mathrm{g})$ was separated by $8 \%$ SDS-PAGE and transferred to a polyvinylidene difluoride membrane. The blot was blocked in PBS containing 0.1\% Tween-20 and 5\% skimmed milk at $37^{\circ} \mathrm{C}$ for $1 \mathrm{~h}$. The membrane was then incubated in primary antibody at $4^{\circ} \mathrm{C}$ overnight, followed by an HRPconjugated secondary antibody. The results were scanned and analyzed using the Scion Image software (Scion, Frederick, Md., USA). Protein levels of TLR 2 and TLR 4 were corrected by $\beta$ actin and the results were shown by relative optical density.

\section{Electrophoretic Mobility Shift Assay of NF- $\kappa B$ Activity}

$\mathrm{NF}-\kappa \mathrm{B}$ activity in rat cardiomyocytes was determined using an electrophoretic mobility shift assay. Nuclear extracts were prepared using the NE-PER kit (Pierce) following the manufacturer's protocol. Equal amounts of nuclear extract protein $(3 \mu \mathrm{g})$ were incubated with $10 \times$ binding buffer, $1 \mu \mathrm{g} / \mu \mathrm{l}$ poly $(\mathrm{dI}-\mathrm{dC})$, and 400-fmol biotin-labeled double-stranded NF- $\mathrm{B}$-binding consensus oligonucleotides 5'-AGTTGAGGGGACTTTCCCAGGC3' (total volume $15 \mu \mathrm{l}$ ) using a LightShift Chemiluminescent electrophoretic mobility shift assay kit (Viagene Biotech). Specificity of binding was ascertained by competition with a 50 -fold excess of unlabeled consensus oligonucleotides. The film was analyzed using Labworks 4.6.

\section{Determination of Myocardial Apoptosis and Necrosis}

Myocardial apoptosis was detected using the terminal deoxynucleotidyl nick-end labeling (TUNEL) assay (Promega, USA). Myocardial nuclei were stained with DAPI (Sigma). TUNEL-positive cardiomyocytes were evaluated under single blinding fashion by a pathologist. The percentage of TUNEL-positive cells was determined by dividing the number of positive-stained nuclei by the total number of nuclei of the cells [16]. Myocardial necrosis was estimated by the release of creatine kinase-MB (CK-MB) and lactate dehydrogenase using an autoanalyzer (model AU5400; Olympus Diagnostics, Melville, N.Y., USA). The LV tissue was stained with hematoxylin and eosin and then assessed in a blinded fashion by a pathologist for the following histological characteristics: acute myocardial necrosis, interstitial edema and cellular swelling.

\section{Estimation of Myocardial Infarct Size}

The size of the myocardial infarction in the 5 groups was estimated by 2,3,5-triphenyltetrazolium chloride (TTC) staining. Briefly, after reperfusion, the hearts were weighed and cut into 2 -mm-thick slices vertical to the atrioventricular groove. The slices were stained by incubation in $1 \%$ TTC solution in phosphate buffer $(0.1 \mathrm{M})$ at $37^{\circ} \mathrm{C}$ for $10 \mathrm{~min}$ and then fixed in $4 \%$ paraformaldehyde solution. Infarct size (unstained by TTC) was measured by planimetry, using the Image Pro Plus 5.0 software (Media Cybernetics, Silver Spring, Md., USA), and expressed as a percentage of the total heart.

\section{Oxidative Stress in LV Tissue}

Maleic dialdehyde (MDA) content and superoxide dismutase (SOD) activity in LV tissue were used as markers of oxidative stress. The MDA content of heart tissue homogenates was measured with a commercially available assay kit (Nanjing Jiancheng). MDA production was read from a standard curve and corrected for tissue protein content (nmol/mg protein). Bradford's method 
Fig. 2. a $\mathrm{O}_{2}$-releasing capacity of PolyPHb during cardiac arrest $(n=15)$. b Cardiac lactic acid release during the first $5 \mathrm{~min}$ of reperfusion. Values are presented as means \pm SEM. ${ }^{*} \mathrm{p}<0.05$ vs. the $\mathrm{HTK}_{9}$ group; ${ }^{\#} \mathrm{p}<0.05$ vs. the $\mathrm{HTK}_{14}$ group.

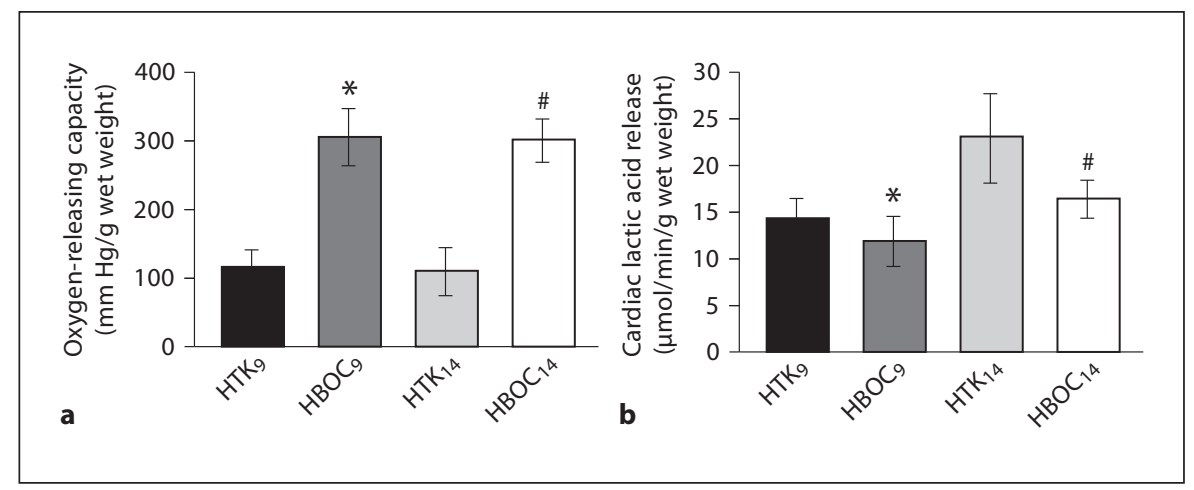

Table 1. Main parameters of PolyPHb in HTKs

\begin{tabular}{ll}
\hline Parameter & Results or range \\
\hline Placenta hemoglobin, g/l & 5 \\
Methemoglobin, \% & $<3$ \\
$\mathrm{P}_{50}, \mathrm{~mm} \mathrm{Hg}^{\mathrm{a}}$ & $5-9$ \\
Colloid osmotic pressure, mm Hg & $20-25$ \\
Osmolality, mosm/kg & $290-310$ \\
Molecular mass, kDa & $64-600$ \\
Unpolymerized hemoglobin, \% & $<3$ \\
\hline
\end{tabular}

${ }^{a} \mathrm{P}_{50}$, the $\mathrm{pO}_{2}$ level at which hemoglobin is half-saturated with $\mathrm{O}_{2}$.

was used to assess protein concentration. The total SOD activity in LV tissue was measured with a commercially available assay kit (Nanjing Jiancheng).

Statistical Analysis

All values are presented as mean \pm SEM. The results of LVDP, LVEDP, $\pm \mathrm{dp} / \mathrm{dt}$ and recovery of CF were analyzed by 2 -factor ANOVA with repeated measures and the use of a post hoc $t$ test with a Bonferroni correction for multiple comparisons. Other data in this study were subjected to 1-way ANOVA followed by a Bonferroni correction for a post hoc $t$ test; $p$ values $<0.05$ were considered to indicate statistical significance.

\section{Results}

\section{Oxygen-Releasing Capacity of $\mathrm{HBOC}$}

Table 1 displays the main parameters of PolyPHb in HTKs and indicates a higher $\mathrm{O}_{2}$ affinity and theoretically higher capacity to carry $\mathrm{O}_{2}$ by PolyPHb (table 1 ). As shown in figure $2 \mathrm{a}$, the $\mathrm{O}_{2}$-releasing capacity of $0.3 \mathrm{~g} \mathrm{Hb} /$ dl PolyPHb was nearly 3-fold higher than that of the HTKs alone $(305.60 \pm 5.43$ vs. $109.86 \pm 4.45 \mathrm{~mm} \mathrm{Hg} / \mathrm{g}$ wet weight; $\mathrm{p}<0.05)$. Consistently, cardiac lactic acid release in the HBOC groups was largely inhibited compared with the HTKs groups $\left(\mathrm{HBOC}_{9} 12.87 \pm 2.54\right.$ and $\mathrm{HBOC}_{14} 16.48 \pm 2.12 \mu \mathrm{mol} / \mathrm{min} / \mathrm{g}$ wet weight vs. $\mathrm{HTK}_{9}$ $15.37 \pm 3.35$ and $\mathrm{HTK}_{14} 24.84 \pm 2.73 \mu \mathrm{mol} / \mathrm{min} / \mathrm{g}$ wet weight, $\mathrm{p}<0.05$, respectively; fig. $2 \mathrm{~b}$ ).

\section{Cardiac LV Function}

At basal perfusion, there was no significant difference in LVDP, $\pm \mathrm{dp} / \mathrm{dt}$, LVEDP or CF among the 5 groups. However, during reperfusion, the LVDP was greatly improved in the HBOC groups when compared with the HTKs groups ( $<<0.05$; fig. $3 \mathrm{a}$ ). The $\pm \mathrm{dp} / \mathrm{dt}$ was also greatly increased in the HBOC groups, compared with the HTKs groups $(\mathrm{p}<0.05$ for both; fig. $3 \mathrm{~b}, \mathrm{c})$. Consistently, the LVEDP elevation after I/R injury was also significantly attenuated in the HBOC groups (vs. the HTKs groups, $\mathrm{p}<0.05$; fig. $3 \mathrm{~d}$ ). Also, the recovery of CF at 60,90 and $120 \mathrm{~min}$ of reperfusion $\left(\mathrm{HBOC}_{9} 72.74 \pm\right.$ $3.52 \%$ and $\mathrm{HBOC}_{14} 50.66 \pm 3.39 \%, \mathrm{p}<0.05$, respectively) of PolyPHb groups was significantly higher than in the HTKs group $\left(\mathrm{HTK}_{9} 58.84 \pm 3.46 \%\right.$ and $\mathrm{HTK}_{14} 37.88 \pm$ $3.82 \%, \mathrm{p}<0.05$, respectively; fig. $3 \mathrm{e}$ ). HBOC did not totally reverse the damage caused by $\mathrm{I} / \mathrm{R}$ injury when compared with the sham group $(\mathrm{p}<0.05)$.

\section{TLR 2,TLR 4, TNF- $\alpha$ and IL-1 $\beta$ mRNA Expression in Cardiomyocytes}

TLR 2, TLR 4, TNF- $\alpha$ and IL-1 $\beta$ mRNA levels of the HBOC groups were markedly lower than in the HTKs groups (fig. $4 a-d ; p<0.05$ ). The mRNA levels of TLR 2 , TLR 4, TNF- $\alpha$ and IL- $1 \beta$ were decreased to a greater extent in the $\mathrm{HBOC}_{14}$ group than in the other groups (TLR $20.35 \pm 0.89$, TLR $40.46 \pm 1.09$, TNF- $\alpha 0.15 \pm 0.75$, IL- $1 \beta 0.20 \pm 0.78$ relative units vs. other groups, $\mathrm{p}<0.05$, respectively). 


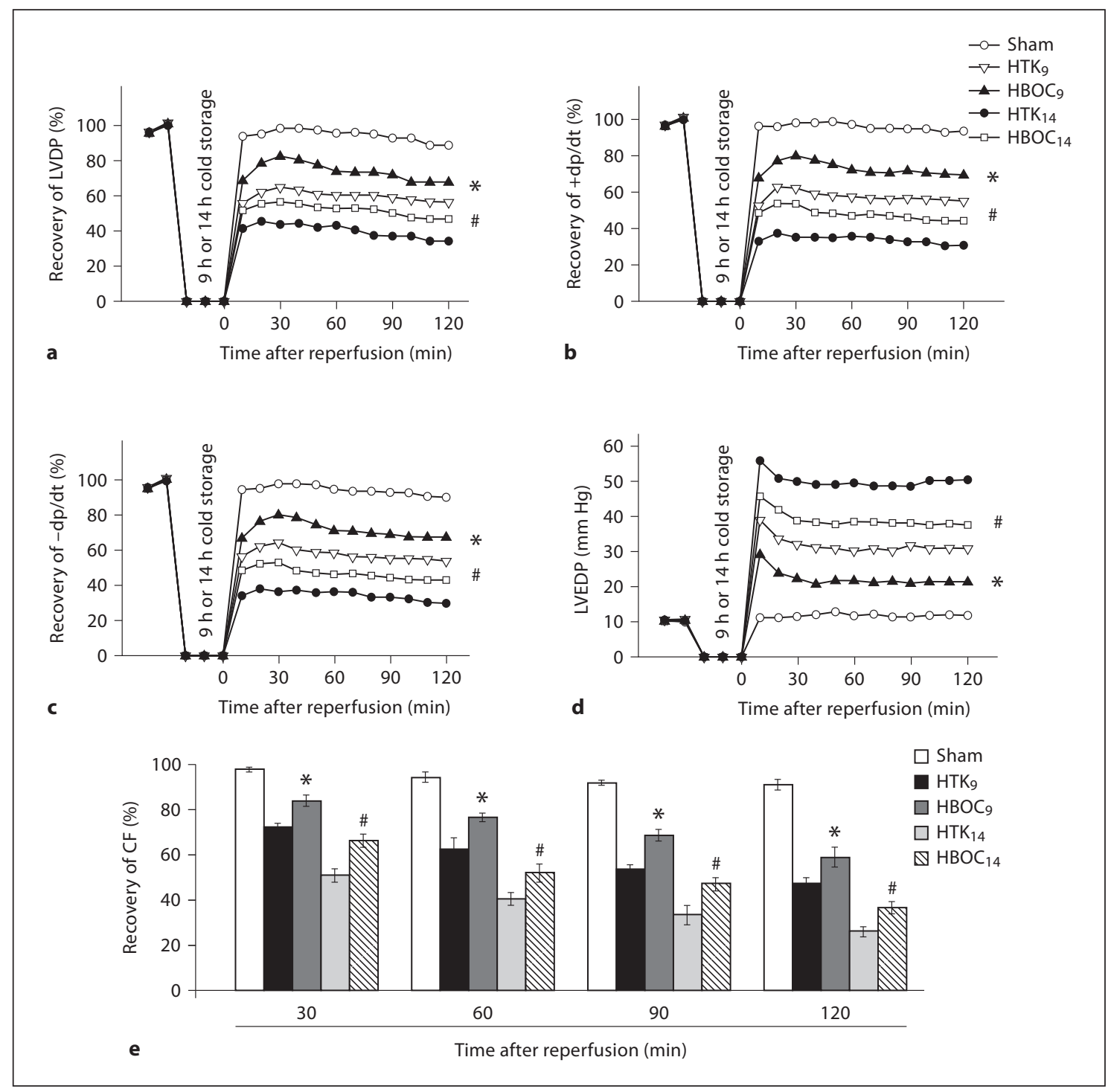

Fig. 3. $\operatorname{LVDP}(\mathbf{a}), \pm \mathrm{dp} / \mathrm{dt}(\mathbf{b}, \mathbf{c})$ and $\operatorname{LVEDP}(\mathbf{d})$ of the 5 groups. e Recovery of CF at baseline and time points of 30, 60, 90 and $120 \mathrm{~min}$ of reperfusion. Values are presented as means \pm SEM $(n=15) .{ }^{*} \mathrm{p}<0.05$ vs. the HTK, group; ${ }^{\#} \mathrm{p}<0.05$ vs. the $\mathrm{HTK}_{14}$ group.

\section{TLR 2 and TLR 4 Protein Levels in Cardiomyocytes}

As shown in figure 5, the Western blotting results showed that TLR 2 and TLR 4 protein levels in HBOC groups were significantly lower than in the HTKs groups $(\mathrm{p}<0.05)$. Protein levels in $\mathrm{HBOC}_{14}$ were markedly lower than other groups (TLR $20.47 \pm 1.12$, TLR $40.28 \pm 1.07$ vs. other groups, $\mathrm{p}<0.05)$.

\section{$N F-\kappa B$ Activity in Cardiomyocytes}

The band gray value of NF- $\mathrm{KB}$ p65/p50 protein was regarded as the corresponding NF- $\mathrm{KB}$ activity (fig. 6a).
The NF- $\kappa \mathrm{B}$ activities in the 5 groups were sham control $79.67 \pm 1.20, \mathrm{HTK}_{9} 84.01 \pm 1.52, \mathrm{HBOC}_{9} 69.01 \pm 1.73$ $\mathrm{HTK}_{14} 104.67 \pm 1.76$, and $\mathrm{HBOC}_{14} 91.33 \pm 1.45$ (the differences among the 5 groups were significant, $\mathrm{F}=$ 36.291; $\mathrm{p}<0.05)$. NF- $\kappa \mathrm{B}$ activity was significantly lower in the HBOC groups than in the HTKs groups $(\mathrm{p}<0.05$; fig. 6b).

\section{Myocardial Apoptosis and Necrosis}

After hypothermic storage $\left(4^{\circ} \mathrm{C}\right)$ for 9 or $14 \mathrm{~h}$ and followed by $2 \mathrm{~h}$ of reperfusion, myocardial apoptosis in the 
Fig. 4. Expression of TLR 2, TLR 4, TNF$\alpha$, and IL-1 $\beta$ mRNA levels in the different experimental groups $(n=15)$. Values are presented as means \pm SEM. ${ }^{*} \mathrm{p}<0.05$ vs. the $\mathrm{HTK}_{9}$ group; ${ }^{*} \mathrm{p}<0.05$ vs. the $\mathrm{HTK}_{14}$ group.

Fig. 5. Western blot analysis of TLR 2 and TLR 4. Representative Western blots of these proteins are shown at the top. Values are expressed as means \pm SEM. ${ }^{*} \mathrm{p}<0.05$ vs. the $\mathrm{HTK}_{9}$ group; ${ }^{*} \mathrm{p}<0.05$ vs. $\mathrm{HTK}_{14}$ group.

Fig. 6. NF- $\mathrm{B}$ p $65 / \mathrm{p} 50$ levels in cardiomyocytes. 1 = Negative control; $2=$ positive control; 3 = sham control; 4 = cold competition reaction; $5=\mathrm{HTK}_{9}$ group; $6=$ $\mathrm{HBOC}_{9}$ group; $7=\mathrm{HTK}_{14}$ group; $8=$ $\mathrm{HBOC}_{14}$ group. NF- $\mathrm{KB}$ activity in the PolyPHb groups was significantly lower. Values are expressed as means \pm SEM. ${ }^{*} \mathrm{p}<0.05$ vs. the HTK 9 group; ${ }^{*} \mathrm{p}<0.05$ vs. the $\mathrm{HTK}_{14}$ group.
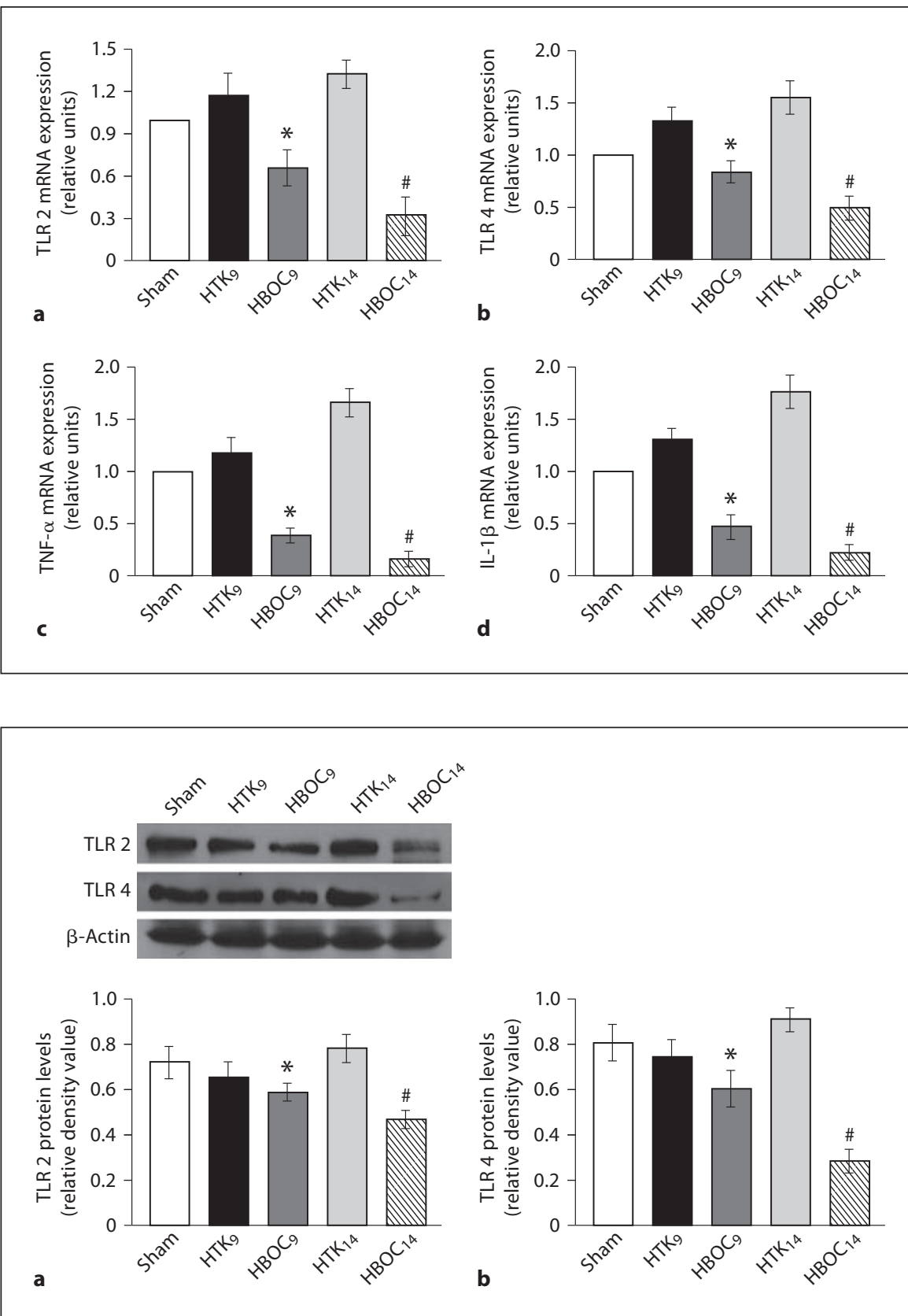

a

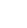

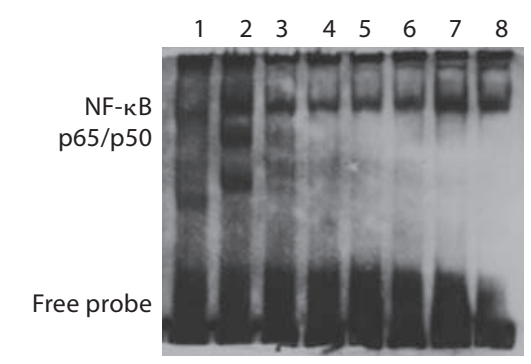

a

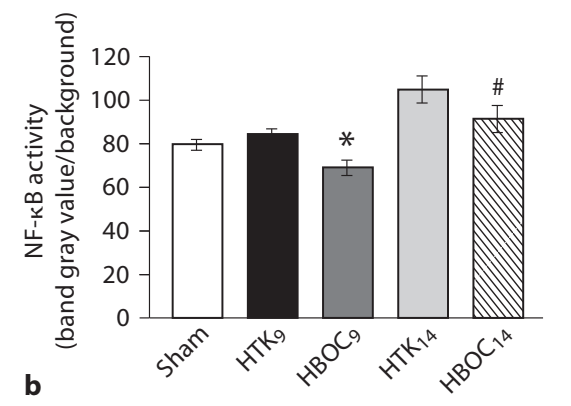




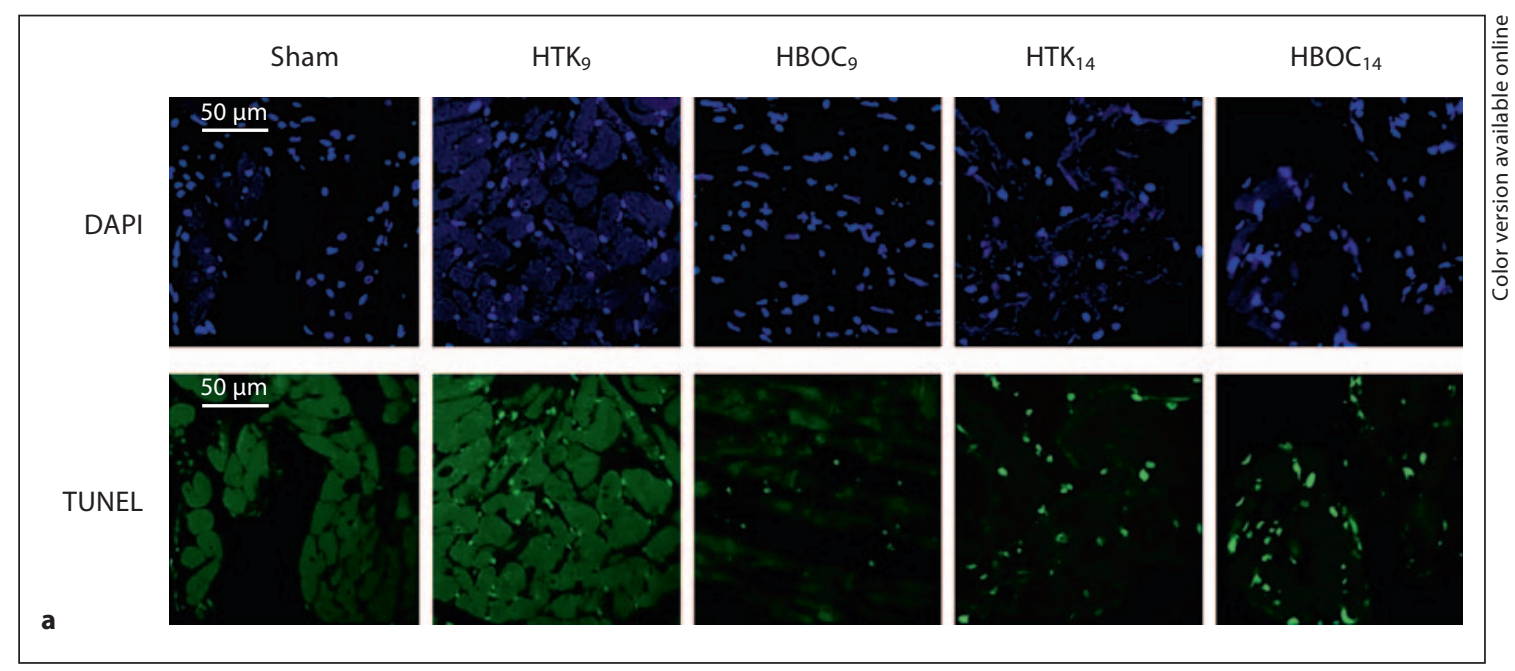

Fig. 7. TUNEL assay. DAPI-stained myocardial nuclei appear light blue, TUNELpositive nuclei appear green (colors refer to the online version only; 5 fields for each specimen). Values are expressed as means \pm SEM. ${ }^{*} \mathrm{p}<0.05$ vs. $\mathrm{HTK}_{9}$ group; ${ }^{\#} \mathrm{p}<$ 0.05 vs. $\mathrm{HTK}_{14}$.

5 groups were: sham control $2.63 \pm 0.89, \mathrm{HTK}_{9} 16.73 \pm$ $1.38, \mathrm{HBOC}_{9} 11.46 \pm 1.15, \mathrm{HTK}_{14} 31.12 \pm 1.72$, and $\mathrm{HBOC}_{14} 22.86 \pm 1.53$ (the differences between the 5 groups were significant; $\mathrm{F}=229.709, \mathrm{p}<0.05)$. The percentage of apoptotic cells was significantly lower in the HBOC groups than in the HTKs groups (fig. 7a, b; p < 0.05 , respectively).

HBOC significantly decreased the percentage infarct size $\left(\mathrm{HBOC}_{9} 13.81 \pm 1.27 \%\right.$ vs. $\mathrm{HTK}_{9} 23.01 \pm 1.72 \%$, $\mathrm{p}<0.05 ; \mathrm{HBOC}_{14} 35.65 \pm 1.84 \%$ vs. $\mathrm{HTK}_{14} 60.39 \pm$ $2.18 \%, \mathrm{p}<0.05$; fig. $8 \mathrm{a}, \mathrm{b})$. HBOC also significantly decreased the release of CK-MB and lactate dehydrogenase into the coronary effluent (vs. the $\mathrm{HTK}_{9}$ group and $\mathrm{HTK}_{14}$ group; $\mathrm{p}<0.05$; fig. $8 \mathrm{c}, \mathrm{d}$ ) and lessened the extent of cellular swelling and extracellular matrix edema (fig. 8e).

\section{Oxidative Stress in LV Tissue}

HBOC significantly increased SOD activity in LV tissue in comparison with the HTK groups $\left(\mathrm{HBOC}_{9} 83.67\right.$ \pm 1.45 and $\mathrm{HBOC}_{14} 66.46 \pm 1.52$ vs. $\mathrm{HTK}_{9} 71.34 \pm 1.85$

and $\mathrm{HTK}_{14} 36.47 \pm 1.28 \mathrm{U} / \mathrm{mg}$ protein, $\mathrm{p}<0.05$; fig. 9a) and decreased the formation of $\mathrm{MDA}\left(\mathrm{HBOC}_{9} 1.21 \pm\right.$ 0.58 and $\mathrm{HBOC}_{14} 1.66 \pm 0.61$ vs. $\mathrm{HTK}_{9} 1.55 \pm 0.62$ and $\mathrm{HTK}_{14} 2.10 \pm 0.96 \mathrm{nmol} / \mathrm{mg}$ protein, $\mathrm{p}<0.05$; fig. $9 \mathrm{~b}$ ).

\section{Discussion}

In this study, we treated isolated rat hearts with $0.3 \mathrm{~g}$ $\mathrm{Hb} / \mathrm{dl} \mathrm{PolyPHb}$ to investigate the potential effect of HBOC on the cold I/R heart. The results demonstrated that HBOC treatment greatly improved cardiac functional recovery compared with the HTK groups. Additionally, myocardial infarction and necrosis were significantly reduced in the HBOC groups, accompanied by significantly elevated myocardial tissue SOD activity and decreased levels of myocardial tissue MDA. To reveal the underlying mechanism, we investigated the TLR/NF- $\kappa \mathrm{B}$ signaling pathway expression in these hearts. We found that HBOC could reduce the mRNA and protein levels of TLR 2 and TLR 4 as well as NF- $\kappa$ B activation. The mRNA 


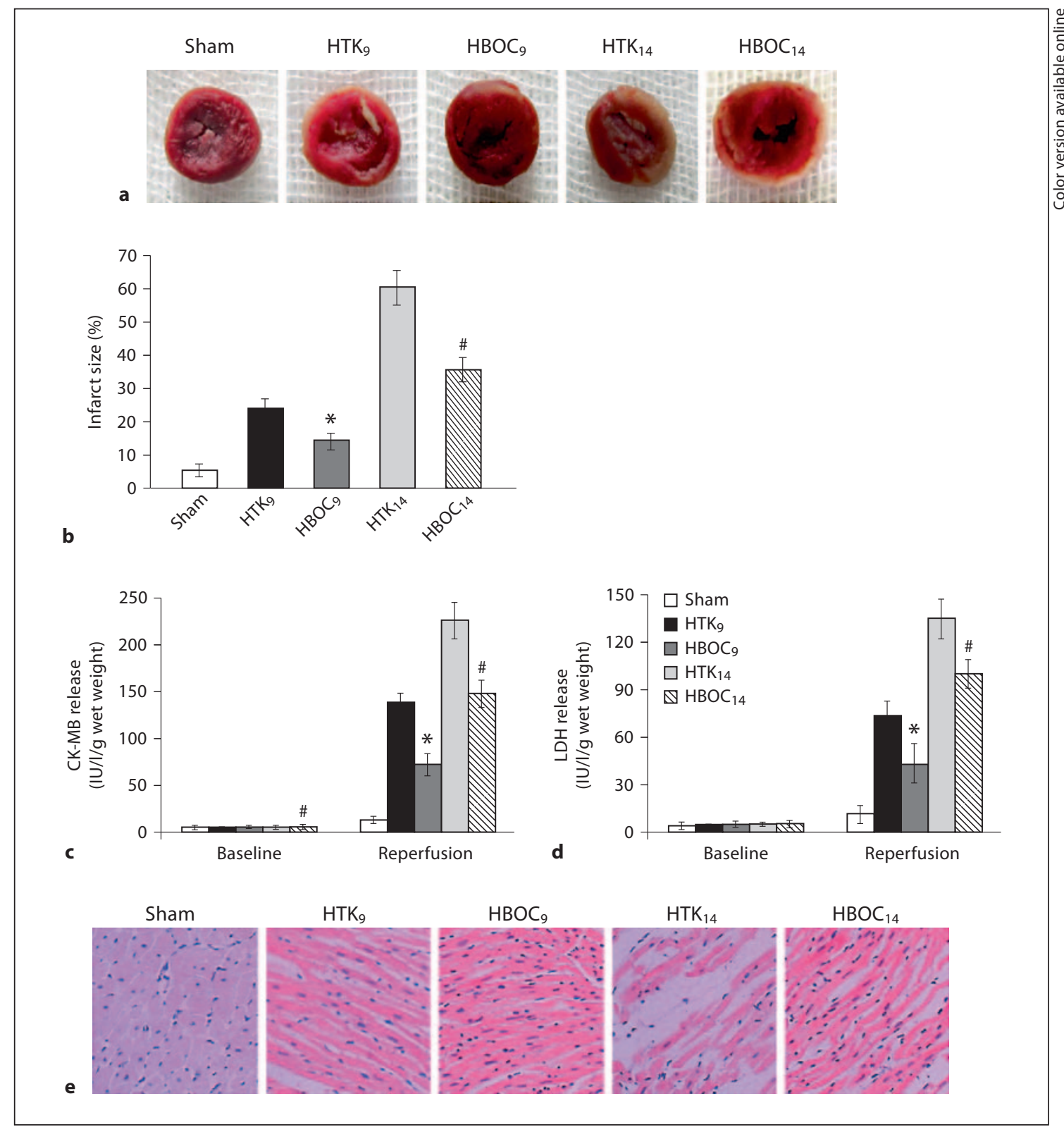

Fig. 8. PolyPHb limits the myocardial infarct size and reduces cardiac enzyme release. a Representative mid-myocardial cross sections of TTC-stained hearts for the 5 groups. Red-stained areas indicate viable tissue and nonstained pale areas indicate infarct tissue. b Myocardial infarct size of hearts in the 5 groups. c, d Total CK-MB and lactate dehydrogenase (LDH) release in coronary effluent after $2 \mathrm{~h}$ of reperfusion. Values are expressed as means \pm SEM. ${ }^{*} \mathrm{p}<0.05$ vs. the $\mathrm{HTK}_{9}$ group; ${ }^{\#} \mathrm{p}<0.05$ vs. the $\mathrm{HTK}_{14}$ group. e Representative photomicrographs of hematoxylin-and-eosin-stained left ventricular tissue sections. Original magnification $\times 400$. levels of TNF- $\alpha$ and IL- $1 \beta$ were consistently significantly decreased. The results indicate that the cardioprotective effect of HBOC on cold I/R injury could be via downregulation of the TLR signaling pathway.

Semi-synthetic or synthetic preparations of hemoglobin, now termed HBOCs, have been in development as an alternative to erythrocytes for several decades. However, nonclinical and clinical studies of HBOCs have raised questions about their safety, presenting an obstacle to their development [17-19]. Thus, in addition to improving the quality of HBOCs themselves, we have started to explore their alternative clinical uses $[12,13,20]$. 
Fig. 9. Oxidative stress in left ventricular tissue. Total SOD activity and MDA formation. One unit of SOD activity corresponded to a $50 \%$ reduction of absorbance at $550 \mathrm{~nm}$. Values are expressed as means \pm SEM. ${ }^{*} \mathrm{p}<0.05$ vs. the $\mathrm{HTK}_{9}$ group; ${ }^{\#} \mathrm{p}<0.05$ vs. the $\mathrm{HTK}_{14}$ group.

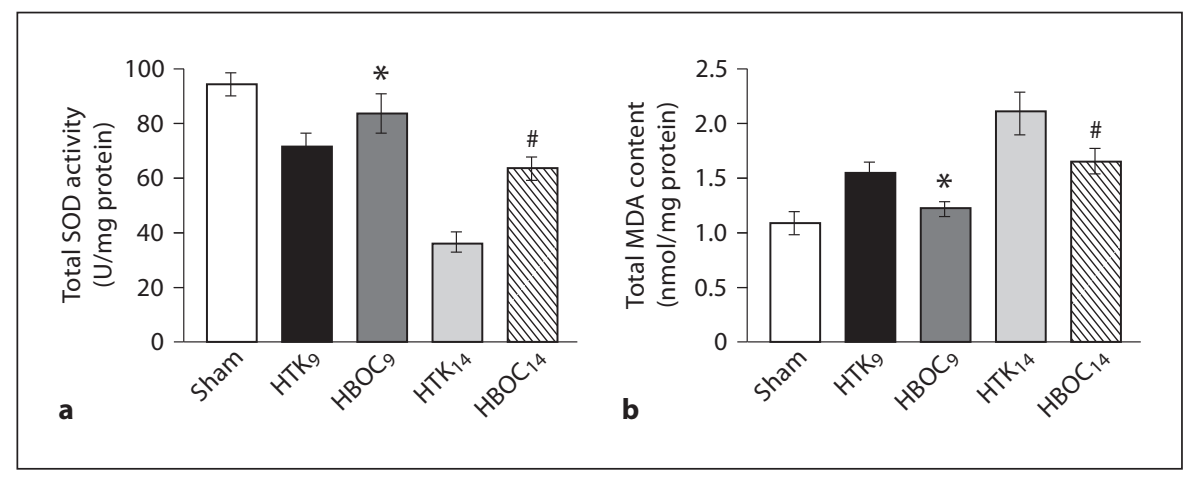

PolyPHb was initially developed as an HBOC by the research group of Prof. Chengmin Yang to treat patients with tumors and hemorrhagic shock [21]. Our previous studies demonstrated that PolyPHb provided more profound protection to the I/R heart than whole blood, showing that the effect of HBOC cannot be totally attributed to its $\mathrm{O}_{2}$-transporting capacity, because it is a multifunctional protein. Moreover, we demonstrated that the cardioprotective effect of PolyPHb was closely related to the attenuation of nitric oxide-mediated myocardial apoptosis and restoration of the nitroso-redox balance in the myocardium $[12,13]$. Animal studies of HBOCs have indicated their potential cardioprotective effects in I/R hearts [22-24]. In our experiments, we tested our hypothesis that the TLR 2 and TLR 4/NF- $\mathrm{KB}$ signaling pathway played an important role in the cardioprotective effects of PolyPHb. The results confirmed the hypothesis and demonstrated the regulatory effect of HBOC on the expression of the TLR 2 and TLR 4/NF- $\mathrm{B}$ signaling pathway for the first time.

As discussed previously, the etiology of myocardial $\mathrm{I} / \mathrm{R}$ injury is multifactorial, but activation of the innate immune system and the resulting inflammatory response are important components of I/R injury. TLRs are a family of proteins that are mammalian homologs of the Drosophila Toll, a protein that functions in development and immunity [25]. TLRs are ubiquitously expressed patternrecognition receptors central to the inflammatory response in a broad variety of species. The TLR/NF- $\kappa$ B signaling pathway has been demonstrated to bridge innate immunity and myocardial I/R injury [26]. TLRs serve as pattern recognition receptors by sensing the presence of conserved microbial motifs and alerting the host to the presence of microbial invaders. Previous studies had also found that TLR 2, TLR 4 and TLR 9 can sense the presence of a number of endogenous molecules termed 'dan- ger-associated molecular patterns' (DAMPs), which include heat-shock proteins, high-mobility-group box 1 , and breakdown products of fibronectin, heparin sulfate and hyaluronic acid [27]. TLR signals can activate NF- $\kappa B$ and NF- $\kappa \mathrm{B}$ then translocates to the nucleus to induce proinflammatory and proapoptotic gene expression promoting cell dysfunction and death [28]. That is to say, the inhibitory effect of HBOC on the mRNA levels of TNF- $\alpha$, IL- $1 \beta$ and NF- $\kappa B$ activation is likely to be associated with decreased TLR 2 and TLR 4 expression, thereby reducing the inflammatory response and myocardial injury during cold $\mathrm{I} / \mathrm{R}$.

Another important finding of this study is the relationship between oxidative stress and expression in the TLR 2 and TLR 4/NF-кB signaling pathway. We found that the HBOC attenuates the fall in SOD and the rise in MDA, respectively. Consistently, the TLR 2 and TLR 4/ NF- $\kappa \mathrm{B}$ signaling pathway expression were significantly inhibited compared with the HTKs groups ( $\mathrm{p}<0.05)$; the reasons for these results are not yet understood. Injury caused by oxidative stress occurs in many clinical scenarios involving ischemia and reperfusion, such as organ transplantation, hemorrhagic shock (HS), myocardial infarction, and cerebral vascular accidents. Molecules released in oxidative stress, such as various reactive oxygen species (ROS) and nitric oxide, are found in response to microbial invasion during the neutrophil and macrophage respiratory burst. Significantly, ROS function not only in their classic role of causing injury by disruption of cell membranes, DNA-strand breaks and enzyme inactivation, but also as precise signaling molecules $[29,30]$. The mechanisms by which redox stress can activate an inflammatory response have not been fully determined. However, there is accumulating evidence that pattern recognition receptors of the innate immune system, such as TLRs, may be involved in mediating the response seen 
in experimental $\mathrm{I} / \mathrm{R}[31,32]$. The TLRs involved in alerting the innate immune system to danger seem to be activated by DAMPs and the mobilization of these DAMPs may represent a link between oxidative stress and the inflammatory response. DAMPs can be released as a consequence of hypoxia and I/R- or hemorrhagic shock-induced injury [33-35], and various types of ROS can contribute to DAMP activation, release and even redox modification $[36,37]$. Activation of the immune system as a result of disturbances in the redox state of cells seems to contribute to tissue and organ damage in these conditions. However, the mechanism by which TLRs mediate the production of ROS during redox stress is uncertain, but could involve the membrane-associated enzyme complex NADPH oxidase [38]. There is also evidence suggesting that interplay between ROS derived from NADPH could modulate the TLRs canonical pathway, initiated by myeloid differentiation factor 88 (MyD88) and calcium-related signaling events [39]. Our study provides a key link connecting the inflammatory response, oxidative stress, innate immunity and hypoxia. PolyPHbinhibited TLR 2 and TLR 4/NF- $\mathrm{KB}$ signaling pathway expression could be via the amelioration of hypoxia and the attenuation of oxidative stress. Understanding the mechanisms of this key interaction may have clinical implications. During ischemic insult, the interaction between oxidative stress and TLR activation forms a paracrine loop, amplifying inflammation, leading to end-organ injury $[40,41]$.
There are several limitations to our study that need consideration. First, because inhibitors of TLR 2 and TLR 4 were not used, we could not exclude the possibility that other mechanisms, such as HBOC, could change the level of other endogenous molecule expression that regulates TLR 2 and/or TLR 4 expression. Second, we demonstrated the dose-related cardioprotective effect of PolyPHb in a previous study [12] and found that an infusion of $0.3 \mathrm{~g}$ $\mathrm{Hb} / \mathrm{dl}$ PolyPHb provided greater myocardial protection during $\mathrm{I} / \mathrm{R}$ than other doses. In this study, we did not research the relationship between different doses of PolyPHb and TLR 2 and TLR 4/NF- $\kappa$ B signaling pathway expression. Further studies are needed to explore this.

In conclusion, the results of our study demonstrated that HBOC was beneficial in the recovery of cardiac function and exerted a profound cardioprotective effect against cold I/R injury. The proposed mechanism for this protection seems to involve the downregulation of TLR 2 and TLR 4/NF- $\mathrm{KB}$ signaling pathway expression. These results reveal that PolyPHb may be useful in the treatment of the myocardial I/R injury in cardiac surgery and transplantation.

\section{Acknowledgments}

This study was supported by a grant from the International S\&T Cooperation (S2010GR0755 to Dr. S.Y. Zheng). Thanks also go to Prof. C.M. Yang for technical assistance and Prof. X.Y. Yu for a critical review of the manuscript.

\section{References}

1 Yellon DM, Hausenloy DJ: Myocardial reperfusion injury. N Engl J Med 2007;357: 1121-1135.

-2 Inserte J, Barrabes JA, Hernando V, Garcia Dorado D: Orphan targets for reperfusion injury. Cardiovasc Res 2009;83:169-178.

-3 Murphy E, Steenbergen C: Mechanisms underlying acute protection from cardiac ischemia-reperfusion injury. Physiol Rev 2008; 88:581-609.

4 Gustafsson AB, Gottlieb RA: Heart mitochondria: gates of life and death. Cardiovasc Res 2008;77:334-343.

-5 Saeed SA, Waqar MA, Zubairi AJ, et al: Myocardial ischaemia and reperfusion injury: reactive oxygen species and the role of neutrophil. J Coll Physicians Surg Pak 2005; 15:507514.

6 Parish RC, Evans JD: Inflammation in chronic heart failure. Ann Pharmacother 2008;42:1002-1016.
7 Miyake K: Innate immune sensing of pathogens and danger signals by cell surface Tolllike receptors. Semin Immunol 2007;19:3.

8 Kaczorowski DJ, Mollen KP, Edmonds R, et al: Early events in the recognition of danger signals after tissue injury. J Leukoc Biol 2008; 83:546.

-9 Mollen KP, Anand RJ, Tsung A, et al: Emerging paradigm: Toll-like receptor 4-sentinel for the detection of tissue damage. Shock 2006;26:430

10 Standl T, Freitag M, Burmeister MA, Horn EP, Wilhelm S, Am Esch JS: Hemoglobinbased oxygen carrier HBOC-201 provides higher and faster increase in oxygen tension in skeletal muscle of anemic dogs than do stored red blood cells. J Vasc Surg 2006;37: 859-865.

-11 George I, Yi GH, Schulman, AR, Morrow BT, Cheng Y, Gu A, Zhang G, Oz MC, Burkhoff D, Wang JA: Polymerized bovine hemoglo- bin oxygen carrier preserves regional myocardial function and reduces infarct size after acute myocardial ischemia. Am J Physiol Heart Circ Physiol 2006;291:H1126-H1137.

12 Li T, Li J, Liu J, Zhang P, Wu W, Zhou R, Li G, Zhang W, Yi M, Huang H: Polymerized placenta hemoglobin attenuates ischemia/ reperfusion injury and restores the nitrosoredox balance in isolated rat heart. Free Radic Biol Med 2009;46:397-405.

13 Li T, Liu J, Yang Q, Wu W, Zhang P, Yang J, Li J, Zhang W, Yang C: Polymerized placenta hemoglobin improves cardiac functional recovery and reduces infarction size of isolated rat heart. Artif Cells Blood Substit Immobil Biotechnol 2009;37:48-52.

14 Yang J, Yang J, Ding JW, Chen LH, et al: Sequential expression of TLR4 and its effects on the myocardium of rats with myocardial ischemia-reperfusion injury. Inflammation 2008;31:304-312. 
15 Vandesompele J, De Preter K, Pattyn F, Poppe B, Van Roy N, De Paepe A: Accurate normalization of real-time quantitative RTPCR data by geometric averaging of multiple internal control genes. Genome Biol 2006; 3:RESEARCH0034.

16 Caswell JE, Strange MB, Rimmer DM 3rd, Gibson MF, Cole P, Lefer DJA: Novel hemoglobin-based blood substitute protects against myocardial reperfusion injury. Am J Physiol Heart Circ Physiol 2005;288:H1796H1801.

17 Serruys P, Vranckx P, Slagboom T, Regar E, Meliga E, de Winter R, Heyndrickx G, Schuler G, van Remortel E, Dubé GP, Symons J: Haemodynamic effects, safety, and tolerability of haemoglobin-based oxygen carrier-201 in patients undergoing PCI for CAD. EuroIntervention 2008;3:600-609.

$>18$ Olofsson C, Nygards EB, Ponzer S, Fagrell B, Przybelski R, Keipert PE, Winslow N, Winslow RM: A randomized, single-blind, increasing dose safety trial of an oxygen-carrying plasma expander (Hemospan) administered to orthopaedic surgery patients with spinal anaesthesia. Transfus Med 2008;18: 28-39.

19 Yu B, Shahid M, Egorina EM, Sovershaev MA, et al: Endothelial dysfunction enhances vasoconstriction due to scavenging of nitric oxide by a hemoglobin-based oxygen carrier. Anesthesiology 2010;112:586-594.

20 Li T, Yu R, Zhang HH, Wang H, Liang WG, Yang XM, Yang CM: A method for purification and viral inactivation of human placenta hemoglobin. Artif Cells Blood Substit Immobil Biotechnol 2006;34: 175-188.

-21 Wu W, Yang Q, Li T, Zhang P, Zhou R, Yang C: Hemoglobin-based oxygen carriers combined with anticancer drugs may enhance sensitivity of radiotherapy and chemotherapy to solid tumors. Artif Cells Blood Substit Immobil Biotechnol 2009;37:163-165.

-22 You Z, Li T, Yang C, Wu H, Zeng Y: Comparison of the cardioprotective effect of deoxygenated hemoglobin-based oxygen carrier (HBOC) pretreatment and ischemia preconditioning. Artif Cells Blood Substit Immobil Biotechnol 2011;39:7-11.
23 Asanuma H, Nakai K, Sanada S, Minamino T, Takashima S, et al: S-nitrosylated and pegylated hemoglobin, a newly developed artificial oxygen carrier, exerts cardioprotection against ischemic hearts. J Mol Cell Cardiol 2007;42:924-930.

24 Burmeister MA, Rempf C, Standl TG, Rehberg S, Bartsch-Zwemke S, Krause T, Tuszynski S, Gottschalk A, Schulte am Esch J: Effects of prophylactic or therapeutic application of bovine haemoglobin HBOC-200 on ischaemia-reperfusion injury following acute coronary ligature in rats. Br J Anaesth 2005;95:737-745.

25 O’Neill LAJ: How Toll-like receptors signal: what we know and what we don't know. Curr Opin Immunol 2006;18:3-9.

26 Oyama J, Blais C Jr, Liu X, et al: Reduced myocardial ischemia-reperfusion injury in Toll-like receptor 4-deficient mice. Circulation 2004;109:784.

27 Sha Y, Zmijewski J, Xu Z, et al: HMGB1 develops enhanced proinflammatory activity by binding to cytokines. J Immunol 2008; 180:2531

28 Liew FY, Xu D, Brint EK, O’Neill LAJ: Negative regulation of Toll-like receptor-mediated immune responses. Nat Rev Immunol 2005;5:446-458.

29 Fialkow L, Wang Y, Downey GP: Reactive oxygen and nitrogen species as signaling molecules regulating neutrophil function. Free Radic Biol Med 2007;42:153-164.

$30 \mathrm{Kim} \mathrm{JH,} \mathrm{Na} \mathrm{HJ,} \mathrm{Kim} \mathrm{CK,} \mathrm{Kim} \mathrm{JY,} \mathrm{Ha} \mathrm{KS,} \mathrm{Lee}$ $\mathrm{H}$, et al: The nonprovitamin A carotenoid, lutein, inhibits NF-кB-dependent gene expression through redox-based regulation of the phosphatidylinositol 3-kinase/PTEN/ Akt and NF- $\mathrm{B}$-inducing kinase pathways: role of $\mathrm{H} 2 \mathrm{O} 2$ in NF- $\kappa \mathrm{B}$ activation. Free Radic Biol Med 2008;45:885-896.

-31 Arslan F, De Kleijn DPV, Timmers L, Doevendans PA, Pasterkamp G: Bridging innate immunity and myocardial ischemia/reperfusion injury: the search for therapeutic targets. Curr Pharm Des 2008;14:1205-1216.

32 Palm NW, Medzhitov R: Pattern recognition receptors and control of adaptive immunity. Immunol Rev 2009;227:221-233.
33 Zahringer U, Lindner B, Inamura S, Heine $\mathrm{H}$, Alexander C: TLR2 - promiscuous or specific? A critical re-evaluation of a receptor expressing apparent broad specificity. Immunobiology 2008;213:205-224.

-34 Aprahamian CJ, Lorenz RG, Harmon CM, Dimmit RA: Toll-like receptor 2 is protective of ischemia-reperfusion-mediated smallbowel injury in a murine model. Pediatr Crit Care Med 2008;9:105-109.

35 Cavassani KA, Ishii M, Wen H, Schaller MA, Lincoln PM, Lukacs NW, et al: TLR3 is an endogenous sensor of tissue necrosis during acute inflammatory events. J Exp Med 2008; 205:2609-2621.

36 Khandoga AG, Khandoga A, Anders HJ, Krombach F: Postischemic vascular permeability requires both TLR-2 and TLR-4, but only TLR-2 mediates the transendothelial migration of leukocytes. Shock 2009;31:592598 .

37 Ito I, Fukazawa J, Yoshida M: Post-translational methylation of high mobility group box 1 (HMGB1) causes its cytoplasmic localization in neutrophils. J Biol Chem 2007;282: 16336-16344.

38 Lambeth JD: NOX enzymes and the biology of reactive oxygen. Nat Rev Immunol 2004; 4:181-189.

39 Kazama H, Ricci JE, Herndon JM, Hoppe G, Green DR, Ferguson TA: Induction of immunological tolerance by apoptotic cells requires caspase-dependent oxidation of highmobility group box-1 protein. Immunity 2008;29:21-32.

40 Park HS, Jung HY, Park EY, Kim J, Lee WJ, Bae YS: Cutting edge: direct interaction of TLR4 with NAD(P)H oxidase 4 isozyme is essential for lipopolysaccharide-induced production of reactive oxygen species and activation of NF-kappa B. J Immunol 2004; 173:3589-3593.

41 Clarke SJ, Khaliulin I, Das M, Parker JE, Heesom KJ, Halestrap AP: Inhibition of mitochondrial permeability transition pore opening by ischemic preconditioning is probably mediated by reduction of oxidative stress rather than mitochondrial protein phosphorylation. Circ Res 2008;102:10821090 